\title{
Model Contrast of Autonomous Vehicle Impacts on Traffic
}

\author{
Derek Hungness $\mathbb{D}^{1}$ and Raj Bridgelall $\mathbb{D}^{2}$ \\ ${ }^{1}$ SRF Consulting Group, 6720 Frank Lloyd Wright Avenue, Suite 100, Middleton, WI 53562, USA \\ ${ }^{2}$ Department of Transportation, Logistics and Finance, North Dakota State University, P.O. Box 6050, Fargo, ND 58108, USA
}

Correspondence should be addressed to Raj Bridgelall; raj@bridgelall.com

Received 23 February 2020; Revised 9 July 2020; Accepted 28 July 2020; Published 14 August 2020

Academic Editor: Giulio E. Cantarella

Copyright (C 2020 Derek Hungness and Raj Bridgelall. This is an open access article distributed under the Creative Commons Attribution License, which permits unrestricted use, distribution, and reproduction in any medium, provided the original work is properly cited.

\begin{abstract}
The adoption of connected and autonomous vehicles (CAVs) is in its infancy. Therefore, very little is known about their potential impacts on traffic. Meanwhile, researchers and market analysts predict a wide range of possibilities about their potential benefits and the timing of their deployments. Planners traditionally use various types of travel demand models to forecast future traffic conditions. However, such models do not yet integrate any expected impacts from CAV deployments. Consequently, many longrange transportation plans do not yet account for their eventual deployment. To address some of these uncertainties, this work modified an existing model for Madison, Wisconsin. To compare outcomes, the authors used identical parameter changes and simulation scenarios for a model of Gainesville, Florida. Both models show that with increasing levels of CAV deployment, both the vehicle miles traveled and the average congestion speed will increase. However, there are some important exceptions due to differences in the road network layout, geospatial features, sociodemographic factors, land-use, and access to transit.
\end{abstract}

\section{Introduction}

Transportation demand modeling has advanced in many ways in recent years, including activity-based modeling and simulation modeling [1]. However, the fundamental approach of the traditional four-step model has remained the same over the past few decades. While various agencies have made enhancements to submodel structures, the basic sequence of trip generation, trip distribution, mode split, and traffic assignment remain unchanged. Recent work completed by the University of Texas Center for Transportation Research presents modifications to a four-step model in order to accommodate two new features: ride-hailing services and autonomous vehicles (AV) [2]. The main changes developed in this work involved splitting households into two groups-AV households and non-AV households-setting potentially different trip generation rates for the new AV households; allowing for AV households to engage in longer trips due to a reduction of value of travel time; the inclusion of ride-hailing as new mode choice stage; and the use of different values of passenger- car-equivalent for AV trips to represent the gains in capacities brought by the use of AVs.

Nevertheless, a void exists between practitioners' use of traditional travel demand forecasting models and rapidly evolving analysis techniques required to address new vehicle capabilities and travel services. This paper begins by recognizing those limitations and proceeds to advance the dialog on transportation systems modeling by analyzing pertinent impact measures within the realm of the traditional four-step travel demand modeling structure. The authors recognize that ongoing advancements in vehicle automation and their wireless connectivity will fundamentally transform transportation and land use. Autonomous vehicles, also known as self-driving vehicles, can reduce the need for urban parking spaces because they can park themselves at remote facilities or provide another ride on demand [3]. Connected and autonomous vehicles (CAVs) can avoid collisions by maintaining constant communication with all vehicles within range to monitor their trajectories. They can help to clear incidents quickly by relaying information to responders and downstream traffic. Therefore, CAVs could increase the capacity of existing 
highways. Further capacity enhancements are achievable by maintaining shorter gaps while traveling faster and anticipating traffic conditions downstream [4]. Since CAVs can travel along narrower paths, reduced width of lanes, shoulders, and medians can provide even greater capacity enhancements [5]. However, there is high uncertainty about impacts during the transition phase of adoption where human and robot drivers must share the road.

There is no certainty about the timing of CAV adoption. Market forecasts suggest some deployments of CAVs will begin by 2025 and market penetration will be as much as $15 \%$ by 2035 [6]. One study found that depending on the levels of willingness to pay, technology cost reduction, and policy changes, CAV adoption by 2045 could range from $24 \%$ to $87 \%$ [7]. A survey of university employees in Memphis, Tennessee, revealed that CAV can reach full adoption by 2050 if prices decrease at an annual rate of $15 \%$ or $20 \%$ [8]. Another study predicts that CAVs will provide independent mobility for affluent nondrivers sometime between 2020 and 2030 [5]. However, Litman notes that the most positive impacts will probably be in the 2040s to 2050s, and the prohibition of human-driven vehicles on certain roadways could take even longer. Overly optimistic predictions for CAV adoption may be due to a priori assumptions on market assimilation of smaller digital innovations. Even though autonomous vehicle travel is a reality today, significant technical problems remain and must be addressed before CAVs can be operated under all conditions and in all areas. Inclement weather, longer life cycle expectancies, wireless service disruptions, affordability, and policy conflicts must be resolved. CAV critical system failures can be fatal. Furthermore, autonomous driving may induce additional vehicle travel which could exacerbate traffic problems.

There is substantial speculation about how much CAVs will affect future travel. A comprehensive international literature review of adoption modeling predicts that CAVs would mostly increase vehicle miles traveled (VMT) and reduce the use of public transit, but the results are very sensitive to model assumptions [9]. Studies generally agree that CAVs would provide greater accessibility for nondrivers such as the young, elderly, and disabled [10]. Researchers argue that increased accessibility for nondrivers will lead to a dramatic increase in VMT [11]. One study posits that greater accessibility for nondrivers will increase travel demand by $11 \%$ [12]. By combining a technology diffusion model and a travel demand model, another study determined that a reduction in the value of travel time and accessibility for new user groups could increase VMT by $3 \%$ to $9 \%$ by 2035 [13]. CAVs could also increase the propensity to travel by more than $4 \%$ and consequently increase car usage by more than $7 \%[14]$.

Transportation network companies (TNCs) such as Uber and Lyft have already increased services at airports, train stations, hotels, shopping malls, and event venues [15]. When fully automated, TNC fleets have the potential to counter the congestion consequences of more VMT because they can move more people in fewer vehicles. In contrast, a mode shift towards cars, a proliferation of private CAVs, and zero occupancy while repositioning vehicles could increase congestion.

CAVs can influence trip frequency, trip length distributions, and mode choice. However, existing models do not reflect the behavioral impacts of CAV deployments. Therefore, without significant CAV deployment, uncertainties remain, and users have little choice but to make certain assumptions [6]. Consequently, many planners avoid the inclusion of CAVs in long-range transportation plans because of the various uncertainties of their impacts [16]. Existing models of travel demand forecasting frequently rely on an assumption that past trends in travel behavior and mode choices will continue for the next few decades with minor alterations. The long-standing practice in transportation planning has been to calibrate models with observed data and then validate them by comparing the outputs to existing conditions. After calibration and validation, planners integrate anticipated sociodemographic and economic trends to predict future outcomes.

A recent tactic to gain insights about possible CAV impacts is to simulate various scenarios by changing certain model parameters [17]. For example, a modification of the Seattle, Washington, activity-based travel model to simulate changes in roadway capacity, value of travel time, and parking costs showed large increases in VMT [18]. Similar modifications to the Charlottesville, Virginia, regional travel demand model showed that a $32 \%$ decrease in capacity during the transition years of adoption could increase vehicle hours traveled (VHT) by $46 \%$, whereas an increase in capacity of $100 \%$ by 2040 could decrease VHT by $13 \%$ [19]. Agent-based modeling suggests that one shared CAV can replace approximately 11 conventional vehicles but will add up to $10 \%$ more VMT than comparable trips in nonshared vehicles [20]. The goal of this paper is to determine the degree to which similar modifications to regional travel demand forecasting models agree. Through official channels, the authors obtained the Madison, Wisconsin, and Gainesville, Florida, models from their respective state departments of transportation. The Gainesville model remained unchanged after acquisition. The contribution of this work is a comparison of forecasts from each model after applying identical parameter changes to forecast potential impacts from CAV deployments. It is important to emphasize here that the parameter changes needed to be the same as those made for the model of another city to allow for direct comparison under identical scenarios to gain and contribute insights into the differences in outcomes.

The organization of the rest of this paper is as follows: Section 2 discusses the methods used to modify the existing models, the scenarios selected for simulation, and model output parameters. Section 3 describes the regional data used and the specific changes made to the models. Section 4 summarizes the model outputs and provides an interpretation of the differences. Section 5 discusses some limitations of the modeling approach. Section 6 reviews the approach and provides some concluding remarks about the general applicability and future work. 


\section{Methods}

The authors selected Madison for comparison with Gainesville because of access and familiarity with those models. Coincidentally, the cities are comparable because of similarities in their sizes and college town settings. Gainesville is the largest city in the north central Florida with a 2017 population of 132,249 . Madison is the second-largest city in Wisconsin with a 2017 population of 255,214 . Colleges significantly influence the travel activities and economy of cities. Gainesville is home to the University of Florida where undergraduate enrollment in 2016 was nearly 40,000. Madison is home to the University of Wisconsin where undergraduate enrollment in 2016 was nearly 30,000. Madison Metro provides public bus transit service throughout the city and to some of its suburbs.

2.1. Current Travel Patterns. The cities of Gainesville and Madison share similar community and transportation system characteristics. Both cities rank within the top 20 places in America for bicycling to work. According to the 2014 American Community Survey, 5.3\% and 4.4\% of Madison and Gainesville workers, respectively, use a bicycle [21]. The same source determined similar average travel time to work for Madison and Gainesville residents existed, 21.6 and 20.5 minutes, respectively, while Madison's commute times have remained relatively stable since then; Gainesville's have increased to now slightly exceed Madison's. Multiple factors can be attributed to Gainesville's relatively short commute travel times, including a strong university-centric public transit system, a compact city layout, centrally located employment centers, and network traffic loads spread throughout the day. A gridded street system helps to evenly distribute traffic, and use of coordinated and active traffic management systems also helps to avoid incidents that would otherwise increase congestion problems [22]. Conversely, Madison's concentration of employment and economic activity is on the downtown isthmus. The isthmus is a constrained geography lying between two lakes which supports high-density office and residential buildings, the state's capitol, the University of Wisconsin campus, and long-established single-family neighborhoods. This leads to a key transportation challenge, the limited number of eastwest connecting arterials through the city [23].

2.2. Scenario Modeling. Modeling the impacts of CAV technology on trip-making requires assumptions on market adoption and penetration rates. This has led to developing representative impacts expected to be caused by CAV integration. In travel demand forecasting models, this is done by altering factors like roadway capacities, vehicle operating costs, mode choice parameters, and origin and destination access and egress times. In November 2017, the U.S. Federal Highway Administration (FHWA) conducted a workshop that defined six CAV scenarios that could occur by 2035 [24]. These scenarios could serve as an early standard for comparing the impacts of CAV adoption across the country. The draft scenarios are as follows:
(1) Slow Roll (Slow). Minimum plausible change, adopts currently available technologies and investments already in motion

(2) Niche Service Growth (Niche). Proliferation of CAV services in niche zones such as retirement communities, campuses, transit corridors, urban cores, and ports

(3) Ultimate Traveler Assist (Assist). State transportation agencies aggressively manage congestion with connected vehicle technology adopted at $85 \%$ by 2035 , but autonomous vehicle adoption stagnates

(4) Managed Lane Network (Managed). $50 \%$ to $60 \%$ of cars and $75 \%$ of trucks platoon on lanes designated for automated vehicles

(5) Competing Fleets (Robo-Mix). VMT doubles because of induced demand and empty vehicle reposition as automated TNC fleets proliferate noncooperatively

(6) Robo-Transit (Robo-PPP). Public-private-partnerships (PPP), cooperative data sharing, policies, and infrastructure modification results in a proliferation of automated TNC services

FHWA's Policy and Strategy Analysis Team completed the Transportation Scenario Planning for Connected and Automated Vehicles study in 2018. The process established a range of plausible scenarios for the deployment and adoption of CAV technologies. Each scenario included common assumptions such as the rapid advancement of mobile technology, 5G cellular connectivity, accepted V2X standards, and passage of rigorous cybersecurity tests. The scenarios progressively intensify connectivity, automation, and cooperation factors. The six CAV scenarios serve to illustrate how local agencies can use similar techniques to develop their own CAV future scenarios. Similarly, the Florida DOT noted that while the FHWA's six CAV future scenarios were used in describing travel demand modifications to represent the future, they are intended to be only guides to local modelers and do not represent the only values or factors that can be modified to reflect CAV implementation.

The goal of this paper is to compare, as directly as possible, the effects of CAV technologies on the Madison transportation system by testing the same future scenario alterations as were published in Florida DOT's work for Gainesville. Identical adjustments of key parameters of both the Gainesville and Madison traditional four-step travel demand models were made to simulate the six scenarios. While many other factors could be tested in the Madison model, the authors determined that this would be the fairest way to compare CAV outcomes and impacts between the two regional travel demand models and cities.

The four-step model integrates submodels for trip generation, trip distribution, mode choice, and network assignment. Table 1 elaborates on the specifics of the modeling methods, their submodel elements, and general parameters of the Madison model and the Gainesville model.

Inputs to the trip generation model are the unique demographic and economic data for the region. Trip 
TABLE 1: Travel model subelement comparison.

\begin{tabular}{lcc}
\hline $\begin{array}{l}\text { Modeling } \\
\text { element }\end{array}$ & Madison, WI & Gainesville, FL \\
\hline Platform & CUBE voyager (scenario manager, application manager, \\
data manager, keys) & $\begin{array}{c}\text { CUBE voyager (scenario manager, application manager, } \\
\text { data manager, keys) }\end{array}$ \\
\hline Time periods & $\begin{array}{c}\text { 3 separate AM peak hours, 3 separate PM peak hours, } \\
\text { midday, night }\end{array}$ & Daily \\
\hline Base year & 2010 & 2010 \\
\hline Future year & 2050 & 2040 \\
\hline Internal zones & 1110 & 560 \\
\hline External zones & 41 & 26 \\
\hline & $\begin{array}{c}\text { Home-based work, home-based shopping, home-based } \\
\text { school, home-based other, non-home-based, home-based } \\
\text { university, single-unit trucks, combination trucks }\end{array}$ & $\begin{array}{c}\text { Home-based work, home-based shopping, home-based } \\
\text { social rec, home-based other, home-based university, } \\
\text { university campus/dorm, non-home-based, } 4 \text {-tire truck, } \\
\text { single-unit trucks, tractor-trailer }\end{array}$ \\
\hline $\begin{array}{l}\text { Trip } \\
\text { generation }\end{array}$ & $\begin{array}{c}\text { Productions: workers, household size x vehicles available } \\
\text { Attractions: employment/school enrollment x coefficients }\end{array}$ & $\begin{array}{c}\text { Productions: household size x dwelling type, autos available } \\
\text { Attractions: employment/dwelling units/school enrollment } \\
\text { x coefficients }\end{array}$ \\
\hline
\end{tabular}

Trip

distribution

Gravity model: person trips by purpose

Gravity model: person trips by purpose

Nested logit: auto drive alone, auto shared ride, drive to Nested logit: auto drive alone, 2-person carpool auto, 3+

Mode split local bus, walk to premium bus, drive to premium bus, bike, person carpool auto, walk to local bus, walk to premium walk bus, drive to transit, bike, walk

Highway

assignment
Equilibrium with incremental loading

distribution requires the geospatial boundaries defined for the various transportation analysis zones (TAZ) of the region and zonal activity level data. TAZ activity levels from households, employment, shopping, and freight movements determine the number of trips produced or attracted. The type of trucks is often associated with the trip type in terms of short-haul urban versus long-haul intercity freight movements. The distance among zones defines a travel impedance between them. This information allows a socalled gravity model to determine how trips will distribute among zones based on their activity levels and the impedances between them. Mode choice typically utilizes a nested logit model to determine a probability of selecting among available modes based on certain attributes such as travel time, travel costs, and accessibility. Network assignment uses the actual roads or transit service available between the different zones to assign generated trips until the result meets some predefined criteria such as traffic equilibrium.

2.3. Model Adjustments. The adjustment of various parameters of a four-step model could simulate potential CAV effects. Table 2 summarizes the adjusted parameters of the Gainesville model. The authors strictly replicated these adjustments for the Madison model.

Friction factors are used in the model to account for the spatial separation between trip origins and designations. It is anticipated that with CAVs, travelers will have greater tolerance for longer distance trips since they will have time to do other tasks instead of operating a vehicle during their commutes. To simulate this effect in the regional models, the friction factors for home-based work trips were increased 2.5 or 5.0 percent, depending on the implementation intensity of the scenario. These amounts represent a slight increase in longer distance work trips made by commuters using automated vehicles as well as the increased availability of automated vehicles to influence housing located further away from employment locations.

Both models use lookup tables to enter roadway capacities to the network. It is assumed that as more automated and connected vehicles appear on the highways, capacities will increase as density balancing will occur with drivers gaining better traveler information and avoiding congested areas and times, as well as more existing roadway space becoming available as CAVs will allow for smaller gaps between vehicles. Both freeways and arterials are anticipated to benefit from these capacity-increasing effects. Three levels of freeway capacity increases were modeled based on slow (33 percent), moderate ( 50 percent), and fast ( 75 percent) adoption rates. Like freeways, three levels of capacity increases were modeled for arterials to represent slow (15 percent), moderate (35 percent), and fast (50 percent) adoption rates.

Terminal times are added to each trip's in-vehicle time. Trip terminal time is controlled by the type of area within which each trip begins or ends. With the increased use of automated vehicles, it is anticipated that terminal times will be reduced as vehicles deliver passengers as close to their destinations as possible. Reductions to the $\mathrm{CBD}$ and adjoining areas of one minute for the Slow Ride and Ultimate Traveler Assist scenarios and two minutes for all other scenarios were tested.

Modifications to the vehicle trip tables were made to accommodate anticipated shifts due to increases or decreases in use of CAVs in certain areas. For example, increases in trips due to the use of automated vehicles by people who currently cannot drive due to age restrictions, 
TABLE 2: FDOT adjustments for CAVs.

\begin{tabular}{lcc}
\hline Factor & CAV effect simulated & Control parameter \\
$\begin{array}{l}\text { Trip length } \\
\text { average }\end{array}$ & $\begin{array}{c}\text { The lengths of trips such as home-based work (HBW) may } \\
\text { increase due to the change in value of time when relieved } \\
\text { from driving }\end{array}$ & $\begin{array}{c}\text { Friction factor (FF) -a factor of the gravity model that sets } \\
\text { the travel impedance among zones. This may change the } \\
\text { trip distribution among zones }\end{array}$ \\
\hline $\begin{array}{l}\text { Roadway } \\
\text { capacity }\end{array}$ & $\begin{array}{c}\text { Density balancing, automatic rerouting, smoother traffic } \\
\text { flows, fewer incidents, and higher throughput from closer } \\
\text { travel gaps and higher speeds }\end{array}$ & $\begin{array}{c}\text { Highway capacity (HC)-lookup table adjustments to the } \\
\text { capacities of freeways and expressways (HC-FE) in the } \\
\text { central business district (CBD), and capacities of divided } \\
\text { arterials (HC-AD) and undivided arterials (HC-AU) in } \\
\text { urban areas }\end{array}$ \\
\hline Accessibility & $\begin{array}{c}\text { Door-to-door service and self-parking will reduce the out- } \\
\text { of-vehicle travel time necessary to access transportation }\end{array}$ & $\begin{array}{c}\text { Terminal time (TT) -lookup table for the factor reduction } \\
\text { in out-of-vehicle travel time in CBD and fringe areas }\end{array}$ \\
\hline Mode choice & $\begin{array}{c}\text { Increased accessibility and door-to-door convenience for } \\
\text { nondrivers may spur a shift away from public transit }\end{array}$ & $\begin{array}{c}\text { Auto trip table-factor increase in trips taken by the current } \\
\text { nondrivers (AT-D) and a factor increase for special zones } \\
\text { that AVs service (AT-S) }\end{array}$ \\
\hline
\end{tabular}

the elderly, or the disabled are anticipated. There may also be a shift from transit-based trips to automobile-based trips with the advent of CAVs.

2.4. Model Output. The four-step models for each city produced four system-wide parameters for each scenario: vehicle miles traveled (VMT), vehicle hours traveled (VHT), average free flow speed, and average congested speed. The model calculated VMT by multiplying the amount of daily traffic recorded for each roadway segment by its length and then summed the individual results. VMT is a measure of demand and a proxy for the level of congestion anticipated. Similarly, the model calculated VHT by dividing the segment VMT by its average travel speed. VHT is a measure of the quality of service that the network provides. Free-flow speed is the average speed that motorists travel when there is no congestion or other adverse conditions. The model calculates congested speed based on the reduction of freeflow speed as a function of the traffic volume to roadway capacity ratio.

\section{Data}

As previously discussed, the model files included the regional data that each model needed to run the various scenarios. Table 3 summarizes the model parameter adjustments used for the Gainesville model [24]. The values shown are the changes in the various parameters defined earlier in Table 2. The FDOT based their adjustments on observations from research conducted throughout the state. The scenarios posit that CAV adoption will lead to an increase in capacity for highways and arterials. In general, the order of the scenarios is from increasing levels of CAV adoption from the "slow" scenario. The exception is the Robo-Mix scenario because fleets are operating noncooperatively, which means that they are not sharing data about traffic and road conditions to help all vehicles make better routing and timing decisions. Terminal times decrease more substantially as adoption increases because of door-todoor service. The friction factors for home-based-work (HBW) trips increase with CAV adoption to reflect a propensity to travel further for work because of a reduction in the value of travel time. The increase in trips for nondrivers is the same for all scenarios. The scenarios for Robo-Mix and Robo-PPP specify a relatively large increase in car use within CAV service zones.

\section{Results}

The horizon years for the original Gainesville and Madison models were 2040 and 2045, respectively. Those remained unchanged to preserve the calibration and validation with their respective baseline year data. The calculated free-flow speeds for Gainesville and Madison were 29.65 MPH and 33.14 MPH, respectively. So, the Madison free-flow speed was approximately $12 \%$ higher. However, after running the models for the baseline future, the average congested speed for Madison was 19\% higher than Gainesville. Table 4 compares the model outputs for the original baseline case and the six CAV scenarios. Figure 1 provides a visualization of the proportional changes in the three outputs from each city's baseline case. The baseline VMT and VHT for Madison was $88 \%$ and $36 \%$ higher, respectively.

The VMT trends for both models generally increased with increasing levels of CAV adoption. The Madison model showed a consistent VMT increase with CAV adoption scenarios. The Gainesville model had an exception in the Ultimate Traveler Assist (Assist) scenario where VMT decreased. The FDOT attributed this exception to the use of more efficient travel routes because of better real-time information [24]. The average VHT for the Madison model increased in all scenarios whereas it decreased for three scenarios in the Gainesville model. The model calculates VHT from congested speed. Both models agreed on the direction of change in congested speed for each scenario. However, the Gainesville model showed a much larger decrease in average congested speed for the Competing Fleets (Robo-Mix) scenario. The FDOT report attributed this to fleet vehicles repositioning and waiting on the next fare [24].

Figures 2 and 3 show the network models for Madison and Gainesville, respectively.

The dense network with dark lines in the center of the map represents the central business districts (CBDs). The differences in spatial arrangements of the two networks are 
TABLE 3: FDOT model adjustments for CAVs adoption scenarios.

\begin{tabular}{lcccccc}
\hline Parameter & Slow & Niche & Assist & Managed & Robo-Mix & Robo-PPP \\
\hline HC-FE & Unchanged & $+33 \%$ & $+75 \%$ & $+75 \%$ & $+50 \%$ & $+75 \%$ \\
HC-AD & Unchanged & $+15 \%$ & $+35 \%$ & $+35 \%$ & Unchanged & $+35 \%$ \\
HC-AU & Unchanged & Unchanged & $+35 \%$ & $+35 \%$ & Unchanged & $+35 \%$ \\
TT & -1 minute & -2 minutes & -1 minute & -2 minutes & -2 minutes & -2 minutes \\
FF & $+2.5 \%$ & $+2.5 \%$ & Unchanged & Unchanged & $+2.5 \%$ & $+5 \%$ \\
AT-D & $+2.5 \%$ & $+2.5 \%$ & $+2.5 \%$ & $+2.5 \%$ & $+2.5 \%$ & $+2.5 \%$ \\
AT-S & $+5 \%$ & $+5 \%$ & Unchanged & $+5 \%$ & $+7.5 \%$ & $+12.5 \%$ \\
\hline
\end{tabular}

TABLE 4: Comparison of model outputs.

\begin{tabular}{lccccc}
\hline \multirow{2}{*}{ Scenarios } & \multicolumn{2}{c}{ VMT (millions) } & \multicolumn{2}{c}{ VHT (thousands) } & \multicolumn{2}{c}{ Congested speed (MPH) } \\
& Gainesville & Madison & Gainesville & Madison & Gainesville \\
\hline Baseline & 11.72 & 22.09 & 373.39 & 506.15 & 26.60 \\
Slow & 11.96 & 22.54 & 391.77 & 517.02 & 26.42 \\
Niche & 11.92 & 22.72 & 381.82 & 515.40 & 26.66 \\
Assist & 11.64 & 23.46 & 340.59 & 509.60 & 27.76 \\
Managed & 11.76 & 24.42 & 340.40 & 530.97 & 27.69 \\
Robo-Mix & 12.14 & 24.63 & 396.98 & 551.58 & 26.30 \\
Robo-PPP & 12.19 & 25.99 & 360.62 & 569.67 & 32.74 \\
\hline
\end{tabular}

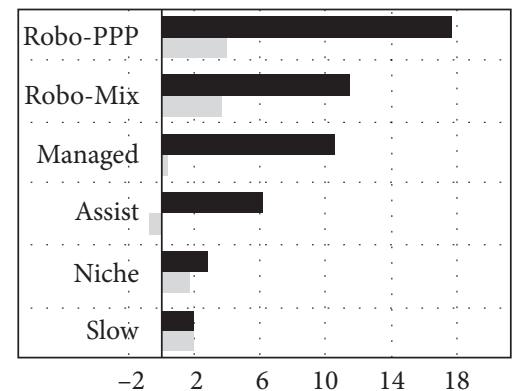

(\%)

Madison

Gainesville

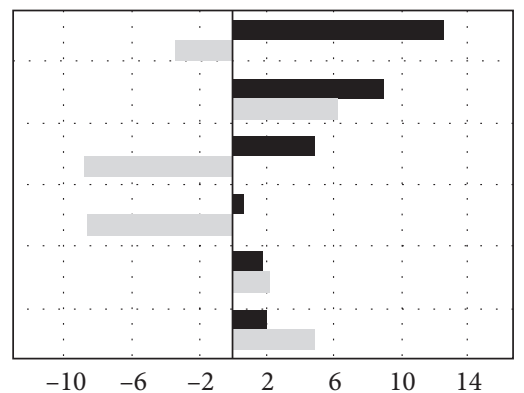

(\%)

Madison

Gainesville

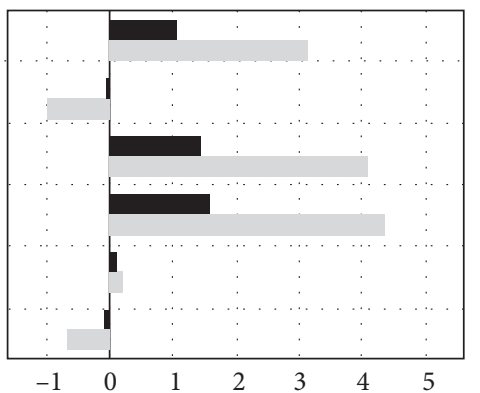

(\%)

Madison

Gainesville

(a)

(b)

(c)

Figure 1: Proportional change of each scenario from the baseline. (a) VMT change. (b) VHT change. (c) Congested speed.

evident. The route restricted land isthmus of the Madison network separates Lake Monona and Lake Mendota and connects major urban districts located on either side of the CBD. The lower density links surrounding the CBD are classified as rural or suburban area types. Table 5 summarizes some of the differences observed between the two networks. These geospatial and network differences help to explain the large VHT differences for some of the CAV adoption scenarios.

CAVs are expected to increase overall route capacities. However, differences in how large geospatial features such as lakes fragment an area and differences in the layout of road networks that provide access to the $\mathrm{CBD}$ are likely reasons for the differences in CAV impact on mobility. For example, additional positive VHT reductions in Madison are likely negated because much of Madison's employment centers are located on a route restricted land isthmus. Unlike the gridlike arrangement of roads in Gainesville, the isthmus is a traffic bottleneck that has no shorter route alternative through it. Furthermore, unlike Gainesville, there is a beltline highway that circumnavigates Madison, and there are very few other east-west routes through the city. This could account for the relatively lower benefits in VHT and congested speed reductions demonstrated by the Madison model.

The Madison model results are further scrutinized given the predicted increase in VHT for all the CAV adoption scenarios. Figure 4 summarizes CAV scenario adoption impacts for specific subareas within the Madison model, which are defined as rural, suburban, urban, and CBD. The results show that VHT gradually increases with CAV adoption intensity in all rural and suburban areas but increases less noticeably in the suburban and CBD areas. This is consistent with the spatial observation that the CBD lacks east-west connecting roads that can provide access to any freeways or arterials where capacity increases due to CAV 


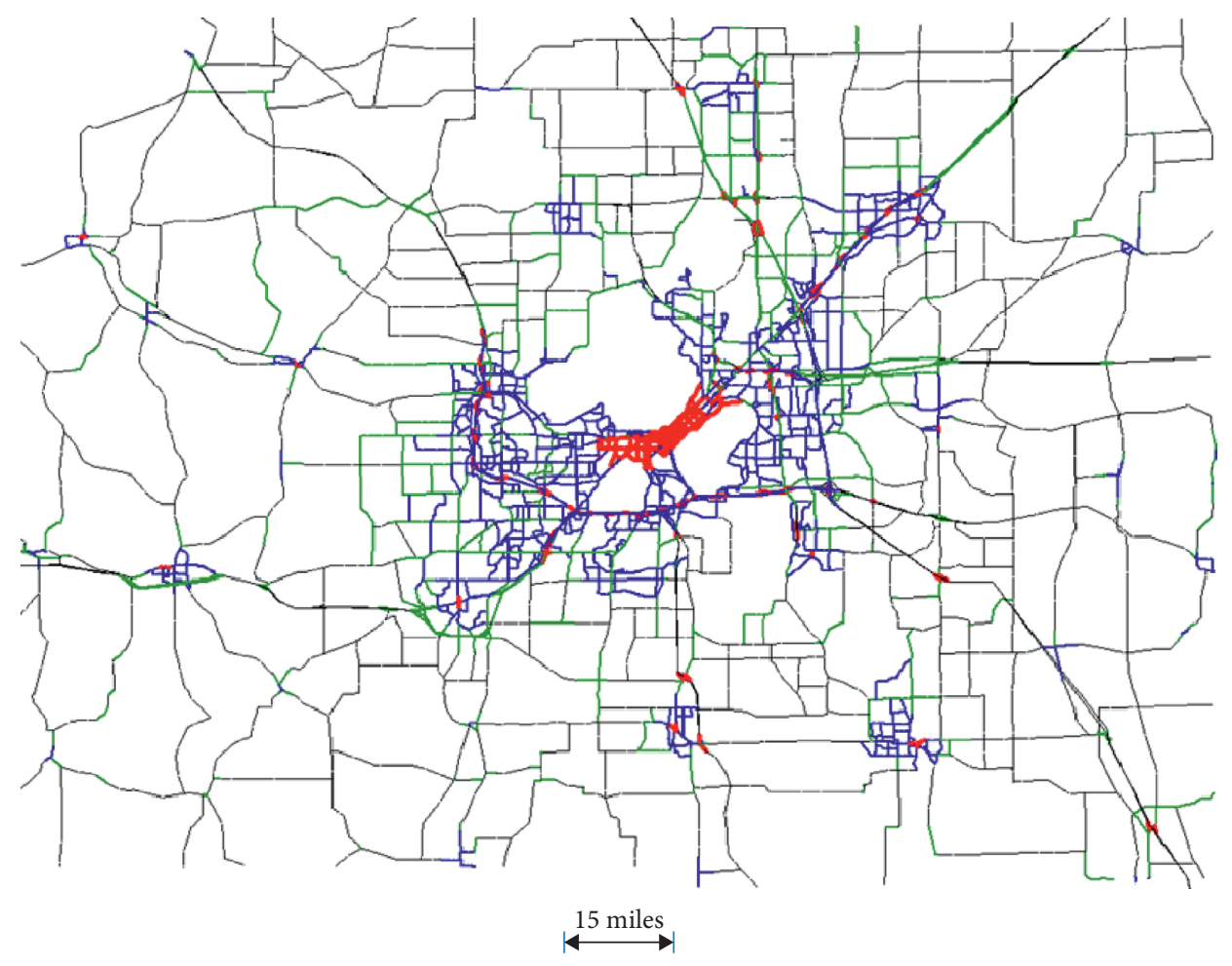

Madison area type
Rural
- Urban
— Suburban
_ Dense urban

Figure 2: Madison model area.

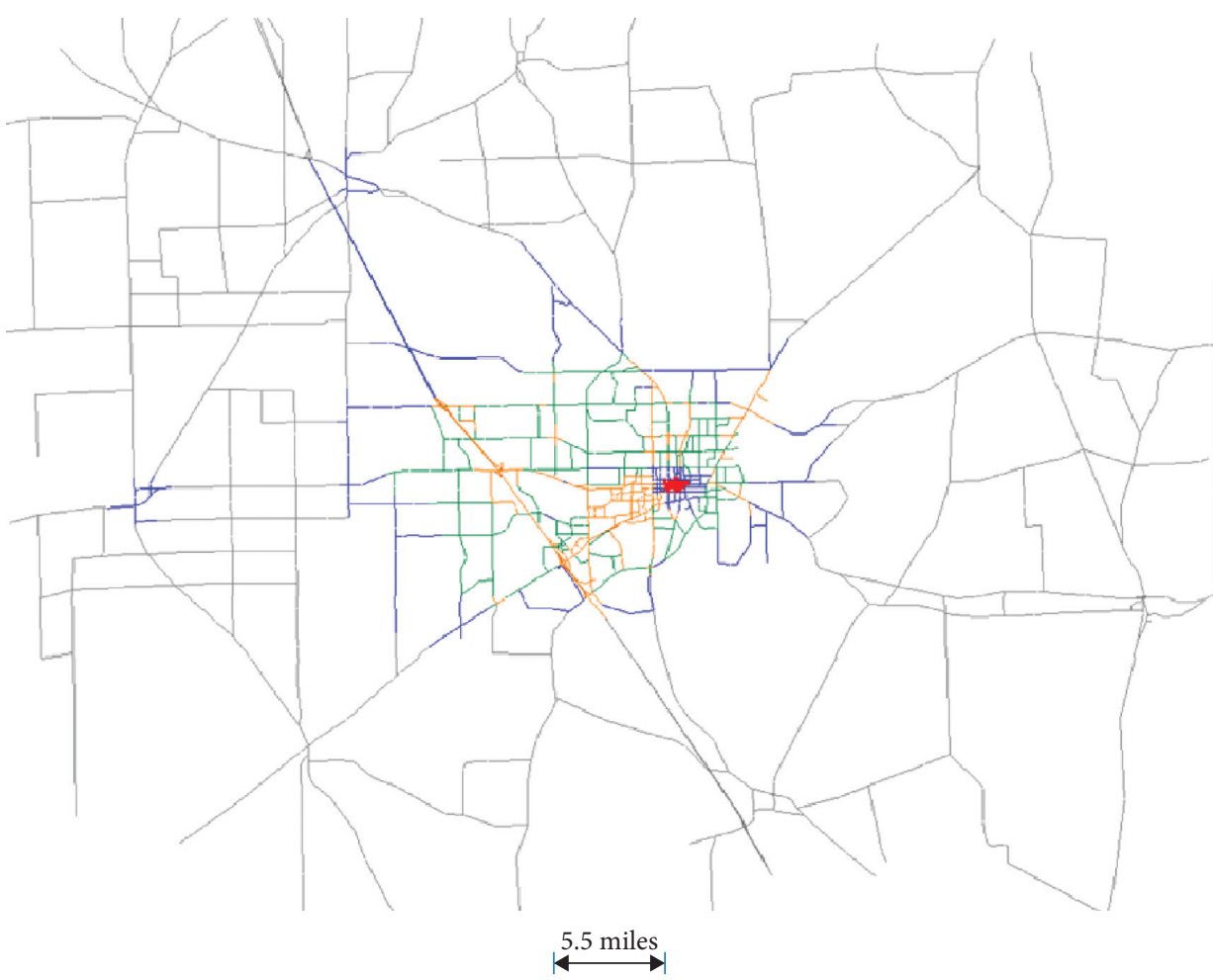

Gainesville area type

_ Urbanized area (CBD)

$\mathrm{CBD}$ fringe area

Undeveloped urbanized area

Rural

__ Residential urbanized area

\author{
— Transitioning areas \\ Outlying business district
}

Undeveloped rural

Figure 3: Gainesville model area. 
TABle 5: Comparison of model networks.

\begin{tabular}{|c|c|c|}
\hline Characteristic & Madison & Gainesville \\
\hline Network layout & $\begin{array}{l}\text { The city center is on an isthmus that separates two lakes } \\
\text { (Mendota and Monona). Four lakes (Mendota, Monona, } \\
\text { Waubesa, and Wingra) fragment the urban network }\end{array}$ & $\begin{array}{c}\text { The city center is a relatively small urban core located to } \\
\text { the east of a major interstate (I-75). No major geographic } \\
\text { features fragment the road network }\end{array}$ \\
\hline $\begin{array}{l}\text { Central business } \\
\text { district }\end{array}$ & $\begin{array}{c}\text { Few roadways on an isolated isthmus with limited access } \\
\text { options to major highways }\end{array}$ & $\begin{array}{l}\text { Many arterials and streets in a dense grid-like pattern } \\
\text { provide many access alternatives, including to I-75 }\end{array}$ \\
\hline $\begin{array}{l}\text { Urban } \\
\text { environment }\end{array}$ & $\begin{array}{l}\text { Distributed around two lakes (Mendota and Monona) } \\
\text { that bloat the spatial distribution of population and } \\
\text { employment }\end{array}$ & $\begin{array}{c}\text { Continuous land mass that concentrates the population } \\
\text { and activity in a relatively small area }\end{array}$ \\
\hline $\begin{array}{l}\text { Urban arterial } \\
\text { network }\end{array}$ & $\begin{array}{l}\text { Curved and diagonal routes with few through-connection } \\
\text { options }\end{array}$ & $\begin{array}{l}\text { Grid-like and linear routes provide many interconnection } \\
\text { options }\end{array}$ \\
\hline $\begin{array}{l}\text { Suburban arterial } \\
\text { network }\end{array}$ & $\begin{array}{c}\text { Heterogenous spatial distribution with limited direct } \\
\text { routes to the CBD }\end{array}$ & $\begin{array}{l}\text { Many route options to the main highway (I-75) that } \\
\text { connects to the CBD }\end{array}$ \\
\hline $\begin{array}{l}\text { Rural } \\
\text { environment }\end{array}$ & Roadways are sparsely distributed & Roadways are more densely distributed \\
\hline Highway access & $\begin{array}{l}\text { Access to the interstate system }(\mathrm{I}-39 / 90 / 94) \text { is via few } \\
\text { arterials that circumnavigate the lakes }\end{array}$ & Five major arterials connect to the interstate (I-75) \\
\hline
\end{tabular}

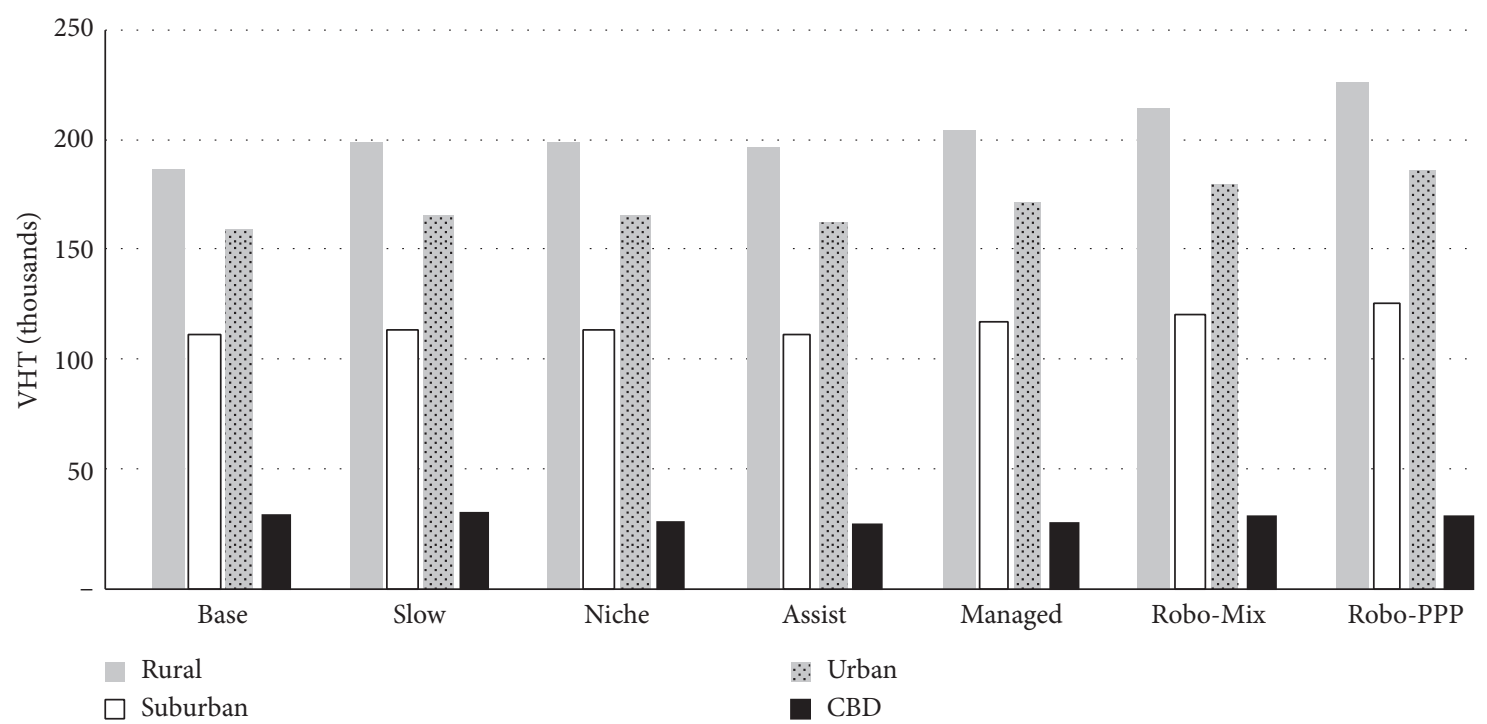

FIgURE 4: Madison 2050 VHT by area and scenario.

adoption could reduce travel times. The stable VHT changes with CAV adoption intensity in the suburban and CBD areas can be explained by additional trips to those areas offsetting increases in capacity.

\section{Discussion}

When CAVs effectively increase the capacity of freeways and arterials, traffic can reroute to rebalance densities. However, the effect will be different among cities because of differences in their geospatial characteristics, land use, and the layout of the roadway network. This case study illustrated how sensitive the forecasted CAV impacts can be to those differences. The change in average congested speed across CAV adoption intensity scenarios was not as pronounced for Madison as it was for Gainesville. All downtown arterials pass through the isthmus in Madison whereas the grid-like layout of arterials in Gainesville creates many route alternatives through the city. Therefore, Madison would be less sensitive to highway and arterial capacity enhancements from CAVs.

The FDOT report also stated that the results varied among regions of Florida [24]. For example, the RoboTransit (Robo-PPP) scenario showed a decrease in VHT for Gainesville but a significant increase for Central Florida. The report attributed the increase in VHT to a larger shift in travel on transit towards Robo-Transit as well as more induced trips from nondrivers. This is plausible because of the significant number of retirees in the area.

This study showed that there are limitations to understanding the potential impacts of CAVs by simply modifying existing forecasting models. For instance, the characteristics of specific zones based on age, income, disability, value of travel time, and other factors may induce different rates of CAV adoption. New models need to incorporate a factor that accounts for the CAV impacts on changes in auto 
ownership and sharing. The integration of smart connected corridors could affect the sensitivity to CAV-related changes in capacity.

\section{Conclusions}

The impacts of connected and autonomous vehicles on trip making and on the roadway system will be significant. The research community generally agrees on how the adoption of CAVs will affect traffic, but they can only speculate on the level of those impacts since there are no significant deployments yet. With such uncertainty, it is nearly impossible to create and validate new travel demand models that incorporate factors such as the elasticity of auto ownership, the propensity to travel, mode choice, and highway capacity. Therefore, the emerging tactic is to adjust the parameters of existing travel forecasting models to simulate the anticipated effects of CAV deployments. This work made identical changes to parameters of the Madison, Wisconsin, model and the Gainesville, Florida, model to compare outcomes.

In order to compare the results of each model run, Vehicle Miles of Travel (VMT), Vehicle Hours of Travel (VHT), and Network Congested Speeds were reported from six plausible future scenarios for Madison and Gainesville. As expected, increases occurred in VMT as more CAVs enter the system. Percent changes from the base condition are much more evident in Madison. VHT measures exhibit greater difference between the Madison and Gainesville models. In Madison, VHT increases for all scenarios, although the Central Business District does not fluctuate as much when individual area types are examined. Increases in average congested speeds were exhibited in both models for three scenarios: Robo-PP, Managed and Assist. Robo-Mix, Niche, and Slow Growth scenarios remained relatively unchanged or decreased slightly in average congested network speed. The results from the Gainesville model appear to be more prominent than for the Madison model in terms of congested speed variance between scenarios.

The results of this study are limited to only two traditional four-step models chosen not only for similarities in community and transportation system composition but also for model availability and convenience. Identical adjustments to inputs, constrained by the originally selected scenarios, were made in order to compare their respective network outputs with increasing CAV adoption. Both models showed that at maximum adoption CAVs will increase VMT, which agrees with the general results from other research studies. The models showed that although VMT would generally increase with CAV adoption levels; some of the scenarios predict exceptions when there are large differences in road network layout, geospatial features, land use, sociodemographic factors, and accessibility to transit. The models also reflect a corresponding increase in the VHT because workers would tend to travel longer distances for home-based work trips when the value of travel time decreases. Although both VMT and VHT increased with higher levels of CAV adoption, the models showed that congested speeds also increased. This is an expected outcome because CAVs can effectively enhance the capacity of a road network. They accomplish this by vehicles following more closely and at higher speeds. Their ability to synchronize movements can smooth out traffic flows. CAVs can also select the most efficient routes in real time.

Planners in other parts of the country can replicate this work and compare results. However, mathematical formulations that relate each step of existing travel demand models can hide details about underlying travel behaviors and CAV effects. Future work will investigate sensitivities of the congested speed for a range of parameter values to discover trends that spatial regression and spatial autocorrelation methods may better explain. The authors intend to expand their work in this area to include further exploration in the sensitivities of four-step models to CAV implementation by introducing additional scenarios and making subsequent representative model adjustments and network testing.

\section{Data Availability}

The data are to be requested directly from the Wisconsin Department of Transportation and the Florida Department of Transportation.

\section{Conflicts of Interest}

The authors declare that they have no conflicts of interest regarding the publication of this paper.

\section{Authors' Contributions}

Study conception and design were carried out by D. Hungness and R. Bridgelall. Data collection was prepared by D. Hungness and R. Bridgelall. Analysis and interpretation of results were contributed by R. Bridgelall and D. Hungness. Draft manuscript preparation was conducted by R. Bridgelall and D. Hungness. All authors reviewed the results and approved the final version of the manuscript.

\section{Acknowledgments}

The authors are grateful to the Wisconsin Department of Transportation for providing the Dane County Travel Demand Forecasting model expressly and exclusively for this research. They are also grateful to the Florida Department of Transportation for providing the Gainesville Travel Demand Forecasting model and supporting documentation.

\section{References}

[1] B. Kaplin and S. Peterson, Connected and Autonomous Vehicles and the Boston MPO - A First Look, Boston Region Metropolitan Planning Organization, Boston, MA, USA, 2017.

[2] G. S. Nair, F. F. Dias, N. Ruiz-Juri, J. Kuhr, and C. R. Bhat, Travel Modeling in an Era of Connected and Automated Transportation Systems: An Investigation in the Dallas-Fort Worth Area, Transportation Research Board, Washington, DC, USA, 2020. 
[3] J. Hawkins and K. Nurul Habib, "Integrated models of land use and transportation for the autonomous vehicle revolution," Transport Reviews, vol. 39, no. 1, pp. 66-83, 2019.

[4] H. Raymond, B. V. Arerm, and S. Hoogendoom, "Automated driving, traffic flow efficiency, and human factors: literature review," Transportation Research Record, vol. 2422, no. 1, pp. 113-120, 2014.

[5] T. Litman, Autonomous Vehicle Implementation Predictions: Implications for Transport Planning, British Columbia: Victoria Transport Policy Institute, Victoria, Canada, 2019.

[6] T. Williams, Transportation Planning Implications of Automated/connected Vehicles on Texas Highways, Texas A\&M Transportation Institute, College Station, TX, USA, 2017.

[7] P. Bansal and K. M. Kockelman, "Forecasting Americans' long-term adoption of connected and autonomous vehicle technologies," Transportation Research Part A: Policy and Practice, vol. 95, pp. 49-63, 2017.

[8] A. Talebian and S. Mishra, "Predicting the adoption of connected autonomous vehicles: a new approach based on the theory of diffusion of innovations," Transportation Research Part C: Emerging Technologies, vol. 95, pp. 363-380, 2018.

[9] A. Soteropoulos, M. Berger, and F. Ciari, "Impacts of automated vehicles on travel behaviour and land use: an international review of modelling studies," Transport Reviews, vol. 39, no. 1, pp. 29-49, 2019.

[10] K. Kockelman, S. Boyles, P. Stone et al., An Assessment of Autonomous Vehicles: Traffic Impacts and Infrastructure Needs, University of Texas at Austin, Austin, TX, USA, 2017.

[11] J. B. Greenblatt and S. Shaheen, "Automated vehicles, ondemand mobility, and environmental impacts," Current Sustainable/renewable Energy Reports, vol. 2, no. 3, pp. 74-81, 2015.

[12] M. Sivak and B. Schoettle, Influence of Current Nondrivers on the Amount of Travel and Trip Patterns with Self-Driving Vehicles, The University of Michigan Transport Research Institute, Ann Arbor, MI, USA, 2015.

[13] S. Trommer, V. Kolarova, E. Fraedrich et al., Autonomous Driving-The Impact of Vehicle Automation on Mobility Behaviour, Institute for Mobility Research (BMW Group), Munich, Germany, 2016.

[14] L. T. Truong, C. De Gruyter, G. Currie, and A. Delbosc, "Estimating the trip generation impacts of autonomous vehicles on car travel in Victoria, Australia," Transportation, vol. 44, no. 6, pp. 1279-1292, 2017.

[15] S. Shaheen, A. Cohen, and I. Zohdy, Shared Mobility: Current Practices and Guiding Principles, U.S. Department of Transportation, Washington, D.C, 2016.

[16] E. Guerra, "Planning for cars that drive themselves," Journal of Planning Education and Research, vol. 36, no. 2, pp. 210224, 2016.

[17] J. Zmud, Updating Regional Transportation Planning and Modeling Tools to Address Impacts of Connected and Automated Vehicles, The National Academies of Science, Washington, DC, USA, 2018.

[18] S. Childress, B. Nichols, B. Charlton, and S. Coe, "Using an activity-based model to explore the potential impacts of automated vehicles," Transportation Research Record: Journal of the Transportation Research Board, vol. 2493, no. 1, pp. 99106, 2015.

[19] J. S. Miller and D. Kang, Ways to Consider Driverless Vehicles in Virginia Long Range Travel Demand Models, Virginia Transportation Research Council, Charlottesville, VA, USA, 2019.
[20] D. J. Fagnant and K. M. Kockelman, "The travel and environmental implications of shared autonomous vehicles, using agent-based model scenarios," Transportation Research Part C: Emerging Technologies, vol. 40, pp. 1-13, 2014.

[21] K. McLeod, Where We Ride: Analysis of Bicycle Communiting in American Cities, The League of American Bicyclists, Washington, DC, USA, 2014.

[22] M. Watkins, For Commuters, Gainesville is Best in Florida, The Gainsesville Sun, Gainesville, FL, USA, 2015.

[23] N. Erdman, Madison in Motion, City of Madison, Madison, WI, USA, 2017.

[24] FDOT, Guidance for Assessing Planning Impacts and Opportunities of Automated, Connected, Electric and Shared-Use Vehicles, Florida Department of Transportation (FDOT), Tallahassee, FL, USA, 2018. 